\title{
Correlates of Coping Styles in Young Women with Type 1 Diabetes
}

\author{
Paulina Wróbel \\ Psychology Institute, Jagiellonian University, Poland
}

Copyright $\bigcirc 2017$ by authors, all rights reserved. Authors agree that this article remains permanently open access under the terms of the Creative Commons Attribution License 4.0 International License

\begin{abstract}
Introduction: Type 1 diabetes mellitus is a chronic disease strongly affected physical and psychical aspects of patient life. It requires self-discipline and regular active participation in the management of the condition. Diabetes is obliged to face a lot of stress and restrictions caused by daily living with disease. Objective: to examine correlates of coping styles in young women with type 1 diabetes mellitus. The aim of the study was particularly concerned with characteristics, which are known to be connected with coping: self-esteem, illness representation, affect, social support and metabolic control. Material and methods: 32 young women (aged 19-30) with type 1 diabetes mellitus were included into the study. The participants completed MSEI, IBS, PANAS, CISS and BSSS. The metabolic status was assessed by $\mathrm{HbA}_{1 \mathrm{C}}$. Results: There were connections between coping styles and self-esteem, illness representation, metabolic control and social support. Relationships between coping styles and affect were not confirmed. Conclusions: The results indicate that the individual characteristics and preferences of young diabetic women such as: their styles of behavior in difficult situations, self-confidence, sense of disease-control, belief in efficacy of medical recommendations and constant necessity of health control should be taken under consideration in the treatment of diabetes.
\end{abstract}

Keywords Type 1 Diabetes Mellitus, Young Women, Coping Styles

\section{Introduction}

Diabetes mellitus is a metabolic disease of unknown etiology characterized by a deficiency of the pancreatic hormone insulin. Primary diabetes mellitus can be subdivided into type 1 and type 2 . Type 1(formerly juvenile onset, insulin-dependent onset) usually appears during childhood or adolescence. Frequently, the diagnosis of diabetes mellitus is related with intensive stress and evokes feelings of guilt, anger, helplessness and hopelessness. The onset is frequently sudden and dramatic, and the patient may experience many symptoms, including ketoacidosis and diabetic coma. Treatment entails life-long treatment with daily urine testing and insulin injections, careful diet control, and planned exercise programs. In spite of such control, microvascular systemic complications frequently occur as do psychological difficulties associated with having a chronic incurable disease [1].

Young people may have problems with maintaining proper metabolic control. Not surprisingly, adolescents have worse metabolic control than younger children and adults. This is partly due to the decrease in insulin sensitivity associated with puberty [2] and partly due to adolescents engaging in poorer self-care behavior [3]. Taking care of diabetes can interfere with the goals of adolescents to establish a sense of independence from parents and to establish a peer group [4]. Moreover, adolescence might be the time during which those with diabetes begin to experience more psychosocial problems compared with healthy peers [5].

There are several reviews of the literature indicating that diabetes is associated with some psychosocial difficulties during childhood and adolescence and these difficulties are more likely in females than males [6,7]. Some study of older adolescents noted an increased risk of psychiatric problems among those with diabetes [8]. Much of the work in this area has focused on depression $[8,9]$ and highlights that up to $20 \%$ of adolescents with type 1 diabetes experience elevated levels of depressive symptoms. There were also reports showing that the symptoms of anxiety are more often in the group of diabetes patients then in the general population $[8,10]$. Moreover, some studies indicate that there are links between the presence of anxiety symptoms, poor adherence and suboptimal glycemic control [11].

Coping styles refer to typical, habitual preferences for ways of approaching problems and might be regarded as strategies that people generally use to cope across a wide range of stressors [12]. Problem-focused coping refers to efforts directed toward rational management of a problem, and it is aimed at changing the situation causing distress. Emotion-oriented coping implies efforts to reduce emotional 
distress caused by the stressful event and to manage or regulate emotions that might accompany or result from the stressors.

The importance of a developmental perspective in understanding the variability in adolescents' coping efforts is underscored [13, 14]. Coping strategies seem to be age dependent, with adolescents using more avoidance coping than younger children with diabetes [15]. It was reported that adolescents who were more easily distressed used more cognitive avoidance and emotional discharge [16]. It has been suggested (Jacobson et al., 1990) that subjects who used more mature defenses and exhibited greater adaptive capacity were more likely to adhere to their regimen. Some reports showed the association of different coping styles with metabolic control and adolescent self-reported diabetes-related quality of life in diabetes [17]. Greater use of active coping was significantly related to a decrease in $\mathrm{HbA}_{1 \mathrm{C}}$ and non-emotion-based coping strategies have been associated with better metabolic control and self-care practices [18, 19, 20, 21, 22]. The studies showed that using problem-oriented strategies of coping was related with better adjustment to illness [20] and receiving more social support [23]. On the other hand, avoidance coping and venting emotions have been found to predict poor illness-specific self-care behavior and were unrelated to worse metabolic control $[24,25,26]$.

Many reports noted that in the group of young people, self-image is significantly connected with accommodation to disease and it's acceptance [27]. In the population of young women with diabetes type 1 emotion-based coping strategies have been associated with self-esteem - all 11 scales of MSEI correlated negatively with the tendency to focus on negative emotions in stressful situations. In the same studies, a relationship between using problem-solving-based coping styles and higher self-esteem was also found [21].

The purpose of the current study is to document correlations between coping styles and self-esteem, illness representation, social support, affect and metabolic control in the population of young women with diabetes mellitus type 1. It is hypothesized that task-oriented coping styles are positively related to self-esteem, adequate illness representation, social support, positive affect and metabolic control, while avoidant-oriented and emotional ones are related negatively with self-esteem, adequate illness representation, social support and metabolic control and positively correlated with negative affect. It is also hypothesized that young women with type 1 diabetes have poor metabolic control.

\section{Materials and Methods}

\subsection{Participants}

The patients were recruited from the diabetic clinics in Silesia. Inclusion criteria for the present study were: age between 19-30 years, sex (female) and diagnosis (type 1 diabetes mellitus). 32 young women with type 1 diabetes who attended the clinics during three months (from April to June 2013) were invited to participate in a study.

\subsection{Measures}

Coping styles were assessed by the Coping Inventory for Stressful Situations (CISS). CISS is used to determine the preferred coping style of an individual and to contribute to understanding of the relationship between coping style and overall personality. The questionnaire consists of 48 statements about different behaviors typical for people in distress. Subjects have to determine on a five-point scale the frequency of a given behavior in stressful, difficult situations. Scores are formatted on three scales:

- $\quad \mathrm{SSZ}$ - task-oriented style: dealing with the problem at hand;

- SSE - emotion-oriented style: focus on consequent emotions (e.g. becoming angry or upset);

- SSU - avoidant style: trying to avoid dealing with a stressor.

The latter can be divided into: $\mathrm{ACZ}$ - distraction seeking: thinking or doing other things; and PKT - social diversion: seeking social support. The questionnaire has high internal consistency of separate scales (coefficients between .78 and .90) [22].

Self-esteem was assessed by Multidimensional Self-Esteem Inventory (MSEI) developed by E. J. O'Brien and S. Epstein and adapted to Polish by Ferenc. This questionnaire measures self-esteem. It consists of 11 scales - one of them directly concerned the global level of self-esteem and eight components regarding detailed aspects of human functioning:

- Competence - evaluation of one's skills and efficacy;

- Lovability - evaluation of forming intimate relationships;

- $\quad$ Likability - evaluation of being liked by others;

- Personal Power - evaluation of one's ability to direct people and influence their behavior;

- Self-Control - evaluation of one's perseverance and ability to control impulses and emotions;

- Moral Self-Approval - evaluation of the level of agreement between one's professed values and their application in life;

- Body Appearance - evaluation of one's appearance and sexual attractiveness;

- Body Functioning - evaluation of one's health and physical fitness.

It also contains an Identity Integration scale which measures global self-concept's cohesion, and a Defensive Self-Enhancement scale which is used to determine the level of need for social approval. The questionnaire contains 116 test items to be graded on a five-point scale and has satisfactory internal consistency of most of the scales (Cronbach's alpha between .70 and .90) and high stability (relationships between two measurements taken in the two weeks interval in the range of .73 to .96) [21]. 
Illness representation was assessed using the Brief Illness Perception Questionnaire (Brief IPQ). The Brief IPQ has nine items, all of which except the causal question are rated using a 0 -to- 10 response scale. Five of the items assess cognitive illness representations:

- consequences (Item 1) - the label the individual uses to describe the illness and the symptoms they view as part of the disease;

- timeline (Item 2) - how long the individual believes the illness will last;

- personal control (Item 3) - the extent to which the individual believes that they control the illness by themselves.

- treatment control (Item 4) - the extent to which the individual believes that can recover from the illness.

- identity (Item 5) - the label the individual uses to describe the illness and the symptoms they view as part of the disease.

Two of the items assess emotional representations: concern (Item 6) - how much the individual is concerned about the illness and emotions (Item 8) - how much the illness affects the individual emotionally. One item assesses illness comprehensibility (Item 7) - the degree to which the patients had an understanding of their illness. The last item is on perceived cause of illness. The Brief IPQ scale has evidence for reliability and validity (Cronbach's $\alpha$ was .72) [28].

To measure social support, the subscales of Perceived support, Need for support and Support seeking from The Berlin Social Support Scales (BSSS) were used. The Berlin Social Support Scales (BSSS) are self-report measures to assess both cognitive and behavioral aspects of social support. There are 6 subscales of the BSSS: Perceived available support, Need for support, Support seeking, Actually received support and Protective buffering support. The answering format is the same for all subscales: patients rate their agreement with the statements on a four-point scale: strongly disagree (1), disagree (2), agree (3), strongly agree (4). Negative items need to be reversed. Scale scores are obtained either by adding up item responses (sum scores) or by generating the scale mean score [29].

Affect was assessed with the Positive and Negative Affect Schedule (PANAS) . The reliability indicator (Cronbach's $\alpha$ ) of PANAS is high and ranges from.73 to .95 . Participants completing the PANAS are asked to rate the extent to which they experienced each out of 20 or 30 emotions on a 5-point Likert Scale. The exact instructions may vary according to the purpose of the study: participants may be asked how they feel right now (S version) or during longer periods of time (C version). Half of the presented emotion words concern negative affect (distressed, upset, guilty, ashamed, hostile, irritable, nervous, jittery, scared, afraid), whereas the other half concern positive affect (interested, alert, attentive, excited, enthusiastic, inspired, proud, determined, strong, active) [30]. In present study the expanded $\mathrm{C}$ version including 30 emotion words (items) was used.
Metabolic control was measured by means of hemoglobin $\mathrm{A}_{1 \mathrm{C}}\left(\mathrm{HbA}_{1 \mathrm{C}}\right) . \mathrm{HbA}_{1 \mathrm{C}}$ values indicate the average blood glucose level over the past 1-2 months. The normal range is $4.5-6.1 \%[31]$.

\subsection{Procedure}

Questionnaires were administered to diabetes patients in the presence of a researcher. A scripted introduction describing the purpose of the questionnaire, patients' rights as research participants and instruction on completing the questionnaire were read to the women. Participants were also told that participation is voluntary and all of their answers would be confidential.

\subsection{Statistical Analysis}

Statistical analyses were carried out using STATISTICA version 6.0. The Shapiro-Wolf test did reveal significant deviations, that's why nonparametric statistics were required. Cronbach's $\alpha$ was used to determine internal consistency reliability for the different coping styles and other characteristic scales. Spearman's rank correlation coefficient was estimated to determine associations between variables. Statistical significance was set at 0.05 .

\section{Results}

Participants including 32 women, 19-30 years of age. All of them used injection as a insulin delivery method. The average $\mathrm{HbA}_{1 \mathrm{C}}$ was $7.77 \%$ indicating that the most of the women in the sample were not meet treatment goals (Table 1).

Table 1. Patient characteristics of 32 women with type 1 diabetes

\begin{tabular}{|c|c|c|}
\hline & Mean or percent & $S D$ \\
\hline Age & 23.47 & 1.43 \\
\hline Duration of diabetes & 7.1 & 3.9 \\
\hline $\begin{array}{c}\text { Insulin delivery } \\
\text { method, injection (\%) }\end{array}$ & 100 & \\
\hline Metabolic control & 7.77 & 1.22 \\
\hline
\end{tabular}

Correlation analyses revealed that all the self-esteem scales were related with coping styles (Table 2). Using task-oriented coping strategies was associated significantly Global Self-Esteem (.34), Lovability (.39), Personal Power (.35), Self-Control (.54) and Identity Integration (.54). There were also significant negative correlations between emotion-oriented style of coping and eight of self-esteem scales. Avoidant style was associated with one self-esteem component - Lovability (.38), however, there were significant correlations between distraction seeking and two MSEI scales - Personal Power (-.42) and Identity Integration (-.36) as also between social diversion and seven self-esteem components (Table 2). 
Table 2. Correlations between coping styles (CISS) and self-esteem (MSEI)

\begin{tabular}{|c|c|c|c|c|c|c|c|c|c|c|c|}
\hline Measure & $\begin{array}{c}\text { Global } \\
\text { Self-esteem }\end{array}$ & Competence & Lovability & Likability & $\begin{array}{c}\text { Personal } \\
\text { Power }\end{array}$ & Self-control & $\begin{array}{c}\text { Moral } \\
\text { Self-approval } \\
\end{array}$ & $\begin{array}{c}\text { Body } \\
\text { Appearance }\end{array}$ & $\begin{array}{c}\text { Body } \\
\text { Functioning }\end{array}$ & $\begin{array}{c}\text { Identity } \\
\text { Integration }\end{array}$ & $\begin{array}{c}\text { Defensive } \\
\text { Self-enhancement }\end{array}$ \\
\hline SSZ & $0.34 *$ & 0.29 & $0.39 *$ & 0.33 & $0.35^{*}$ & $0.54 *$ & 0.31 & 0.34 & 0.26 & $0.54 *$ & 0.25 \\
\hline SSE & $-0.52 *$ & $-0.57 *$ & -0.29 & $-0.39 *$ & $-0.37 *$ & -0.35 & -0.15 & $-0.45^{*}$ & $-0.44 *$ & $-0.44 *$ & $-0.42 *$ \\
\hline SSU & 0.14 & -0.26 & $0.38^{*}$ & -0.09 & -0.34 & 0.01 & -0.02 & 0.23 & 0.21 & -0.14 & 0.29 \\
\hline $\mathrm{ACZ}$ & -0.08 & -0.33 & 0.04 & -0.14 & $-0.42 *$ & -0.25 & -0.13 & -0.10 & -0.08 & $-0.36^{*}$ & -0.05 \\
\hline PKT & $0.42 *$ & 0.02 & $0.61 *$ & $0.37^{*}$ & -0.12 & $0.37^{*}$ & 0.18 & $0.52 *$ & $0.49^{*}$ & 0.19 & $0.52 *$ \\
\hline
\end{tabular}

Note. $* \mathrm{p}<.05$

SSZ - task-oriented style; SSE - emotion-oriented style; SSU -avoidant style; ACZ - distraction seeking; PKT - social diversion 
Table 3. Correlations between coping styles (CISS) and illness representation (Brief IPQ)

\begin{tabular}{|c|c|c|c|c|c|c|c|c|}
\hline Measure & Consequences & Timeline & $\begin{array}{c}\text { Personal } \\
\text { Control }\end{array}$ & $\begin{array}{c}\text { Treatment } \\
\text { Control }\end{array}$ & Identity & $\begin{array}{c}\text { Emotional } \\
\text { Representations: } \\
\text { Concern }\end{array}$ & $\begin{array}{c}\text { Illness } \\
\text { Comprehensibility }\end{array}$ & $\begin{array}{c}\text { Emotional } \\
\text { Representations: } \\
\text { Emotions }\end{array}$ \\
\hline SSZ & -0.18 & -0.14 & 0.34 & $0.41^{*}$ & -0.27 & -0.3 & 0.17 & -0.18 \\
\hline SSE & 0.15 & -0.20 & $-0.39^{*}$ & -0.17 & 0.12 & 0.01 & -0.24 & 0.21 \\
\hline SSU & -0.17 & -0.09 & 0.09 & 0.16 & $-0.39^{*}$ & -0.31 & 0.01 & $-0.42^{*}$ \\
\hline ACZ & -0.02 & -0.08 & 0.12 & 0.1 & -0.21 & -0.14 & 0.01 & -0.2 \\
\hline PKT & -0.31 & -0.3 & 0.1 & 0.2 & $-0.45^{*}$ & $-0.42^{*}$ & 0.19 & $-0.46^{*}$ \\
\hline
\end{tabular}

Note. $* \mathrm{p}<.05$

Table 4. Correlations between coping styles (CISS) and social support (BSSS)

\begin{tabular}{|c|c|c|c|c|c|}
\hline Measure & SSZ & SSE & SSU & ACZ & PKT \\
\hline Perceived available support & $0.38^{*}$ & -0.27 & 0.12 & -0.17 & $0.37^{*}$ \\
\hline Need for Support & 0.09 & 0.44 & 0.24 & 0.1 & 0.26 \\
\hline Support Seeking & $0.37^{*}$ & -0.17 & 0.11 & -0.13 & 0.33 \\
\hline
\end{tabular}

Note. ${ }^{*} \mathrm{p}<.05$

Table 5. Correlations between coping styles (CISS) and affect (PANAS) and between coping styles (CISS) and glycemic control (HbA $\left.\mathrm{H}_{1 \mathrm{C}}\right)$

\begin{tabular}{|c|c|c|c|c|c|}
\hline Measure & SSZ & SSE & SSU & ACZ & PKT \\
\hline HbA $_{1 C}$ & -0.33 & 0.07 & $-0.39^{*}$ & -0.25 & $-0.36^{*}$ \\
\hline positive affect & -0.39 & 0.1 & 0.18 & 0.07 & 0.3 \\
\hline negative affect & -0.03 & 0.23 & 0.16 & 0.09 & 0.2 \\
\hline
\end{tabular}

Note. ${ }^{*} \mathrm{p}<.05$

Some significant correlations were found between coping styles and illness representation (Table 3). SSZ was associated with treatment control (.41), SSE - with Personal Control (-.39) and SSU - with Identity (-.39) and Emotional Representations: Emotions (-.42). There were also significant correlations between diversion seeking and three Brief IPQ scales: Identity (-.45), Emotional Representations: Concern (-.42) and Emotional Representations: Emotions (-.46).

Two of social support scales were significantly associated with task-oriented coping style: Perceived available support (.38) and Support seeking (.37). PKT was also related positively with Perceived available support (.37) (Table 4).

The study evidenced some correlations between coping styles and glycemic control. $\mathrm{HbA}_{1 \mathrm{C}}$ was related negatively with SSU scale (-.39) and its subscale - social diversion (-.36) (Table 5). However, no significant correlation between affect and coping styles was found (Table 5).

\section{Discussion and Conclusion}

The main aim of the study was to examine correlates of coping styles in young women with type 1 diabetes. Hypothesized associations between coping styles and other measures were partially confirmed. In the group of participants using task-oriented strategies was related with higher global self-esteem, having more treatment control over the illness, perceiving more social support and having better glycemic control. These findings are consistent with previous studies about task-oriented coping style's correlates $[18,20,21,22,30]$.

The analyses revealed associations between emotional-oriented coping style and self-esteem. Using emotion-oriented coping strategies was negatively related to global self-esteem and its components except Lovability and Moral Self-Approval. That relations were similar to those presented in the previous study [21]. The negative correlation between illness representation scale - Personal Control and SSE was also found. No association between social support scales and emotion-oriented coping style was confirmed as well as between $\mathrm{HbA}_{1 \mathrm{C}}$ and SSE. Similarly, some previous studies also demonstrated the lack of correlation between using emotion-oriented coping strategies and glycemic control [24]

The study indicate that avoidant-oriented coping style was related negatively with two illness representation scales Identity and Emotional Representation: Emotions. There was also negative correlation between SSU and glycemic control. Similar results were detected in previous studies $[20,24,27]$. Further correlation analyses revealed that the subscale of SSU - ACZ was found to be negatively related with two self-esteem components - Personal Power and Identity Integration, while the second SSU subscale - PKT was associated with higher global self-esteem and better glycemic control. Social diversion (PKT) was also related negatively with three Illness Representation components Identity, Emotional Representation: Emotions and 
Emotional Representation: Concern. These results show that using some avoidant-oriented coping strategies, as seeking social diversion, may be adaptive in managing diabetes.

Consistent with previous research, It was also found that young patients have difficulties maintaining metabolic control [2, 3], however, no hypothesized association between affect and coping style was confirmed. Analyses showed that the tendency to experience positive or negative emotions is not connected with coping styles in young women with type 1 diabetes. These results are not consistent with previous studies $[7,32]$ and could be caused by using a specific method to assess affect - in the previous studies STAI and BDI were used and researches were focused on documenting negative emotions (anxiety and depression symptoms) connected with coping styles. In this study positive affect was also measured, using PANAS instead of depression or anxiety scales. On the other hand, many studies on affect have been carried out on patients with type 2 diabetes. Type 2 diabetes is distinctly different disease then diabetes type 1 . Moreover, patients with type 2 diabetes are usually older than patients with diabetes type 1 . This question needs more analysis - one avenue for future research is to recruit more patients with type 1 diabetes, both women and men. Another avenue is to test other psychological issues (for example quality of life) that could be related to good metabolic control or adequate illness representation.

The results of the present study may have potentially important implications for treatment and living with diabetes type 1. Evidenced positive correlations between task-oriented style and self-control (MSEI) as well as treatment control (Brief IPQ) give information about issues that can be important for patient, their families and medical staff for treating and managing diabetes. Presented results indicate that training problem-solving strategies of coping may help to increase sense of personal control over disease and improve glycemic control.

In summary, presented findings show that diabetes treatment should consider the individual traits and preferences of young female patients, such as: coping style in stressful situations, self-esteem, illness personal control, effectiveness of treatment and self-monitoring, as also the emotional impact of the disease on their functioning. Training proper coping strategies can be important for maintaining good physical and psychological health of young diabetes patients. Social support and family acceptance are also significant for coping with glycemic control, which plays a crucial role in healthy functioning and minimizing the risk of future complications. Sharing knowledge about psychological issues that are related with better illness control could help in the individual adaptation of effective treatment for diabetes type 1 .

\section{REFERENCES}

[1] Parker, P. D. Relationship between self-esteem and depression and adolescent diabetic control (Doctoral dissertation, The University of Utah), 1982

[2] Lehmkuhl, Heather D., et al. "Perceptions of type 1 diabetes among affected youth and their peers." Journal of clinical psychology in medical settings 16.3 (2009): 209-215.

[3] Ellis, Deborah A., et al. "The role of parental monitoring in adolescent health outcomes: Impact on regimen adherence in youth with type 1 diabetes." Journal of Pediatric Psychology 32.8 (2007): 907-917.

[4] Helgeson, Vicki S., et al. "Comparison of adolescents with and without diabetes on indices of psychosocial functioning for three years." Journal of Pediatric Psychology 32.7 (2007): 794-806.

[5] Helgeson, V. S., Snyder, P. R., Escobar, O., Siminerio, L., \& Becker, D. (2007). Comparison of adolescents with and without diabetes on indices of psychosocial functioning for three years. Journal of Pediatric Psychology, 32(7), 794-806.

[6] Helgeson, Vicki S., et al. "Predictors of metabolic control among adolescents with diabetes: a 4-year longitudinal study." Journal of Pediatric Psychology 34.3 (2009): 254-270.

[7] McNally, Kelly, et al. "Executive functioning, treatment adherence, and glycemic control in children with type 1 diabetes." Diabetes Care 33.6 (2010): 1159-1162.

[8] Delamater, Alan M. "Psychological care of children and adolescents with diabetes." Pediatric Diabetes 10.s12 (2009): 175-184.

[9] McGrady, Meghan E., et al. "Depressive symptoms and glycemic control in adolescents with type 1 diabetes." Diabetes care 32.5 (2009): 804-806.

[10] Compas, Bruce E., et al. "Coping with chronic illness in childhood and adolescence." Annual Review of Clinical Psychology 8 (2012): 455-480.

[11] Helgeson, Vicki S., et al. "Parent and adolescent distribution of responsibility for diabetes self-care: Links to health outcomes." Journal of Pediatric Psychology 33.5 (2008): 497-508.

[12] Carver, Charles S., Michael F. Scheier, and Jagdish K. Weintraub. "Assessing coping strategies: a theoretically based approach." Journal of personality and social psychology 56.2 (1989): 267.

[13] Aldwin, Carolyn M. Stress, coping, and development: An integrative perspective. Guilford Press, 2007.

[14] Zimmer-Gembeck, Melanie J., and Ellen A. Skinner. "Review: The development of coping across childhood and adolescence: An integrative review and critique of research." International Journal of Behavioral Development 35.1 (2011): 1-17.

[15] Lawrence, Jean M., et al. "Prevalence and correlates of depressed mood among youth with diabetes: the SEARCH for Diabetes in Youth study." Pediatrics 117.4 (2006): 1348-1358.

[16] Eschenbeck, Heike, Carl-Walter Kohlmann, and Arnold Lohaus. "Gender differences in coping strategies in children and adolescents." Journal of individual differences 28.1 (2007): $18-26$. 
[17] Seiffge-Krenke, Inge. Stress, coping, and relationships in adolescence. Psychology Press, 2013.

[18] Broadbent, Elizabeth, et al. "The brief illness perception questionnaire." Journal of psychosomatic research 60.6 (2006): 631-637.

[19] Brzozowski P., Skala uczuć pozytywnych i negatywnych SUPIN. Polska adaptacja skali PANAS Davida Watsona i Lee Anny Clark. Podręcznik. Warszawa: Pracownia Testów Psychologicznych Polskiego Towarzystwa Psychologicznego, 2010.

[20] Aldwin, Carolyn M. Stress, coping, and development: An integrative perspective. Guilford Press, 2007.

[21] Ferenc D. MSEI - Wielowymiarowy Kwestionariusz Samooceny. Warszawa: Pracownia Testów. Psychologicznych, 2008.

[22] Strelau J., Jaworowska A., Wrześniewski K., Szczepaniak P. CISS Kwestionariusz radzenia sobie w sytuacjach stresowych. Warszawa, 2009.

[23] DiMatteo, M. Robin. "Social support and patient adherence to medical treatment: a meta-analysis." (2004): 207.

[24] Compas, Bruce E., et al. "Coping with chronic illness in childhood and adolescence." Annual Review of Clinical Psychology 8 (2012): 455-480.

[25] Hood, Korey K., et al. "Association between adherence and glycemic control in pediatric type 1 diabetes: a meta-analysis." Pediatrics 124.6 (2009): e1171-e1179.

[26] Hema, D. A., et al. "Daily stressors and coping responses of children and adolescents with type 1 diabetes." Child: care, health and development 35.3 (2009): 330-339.

[27] DiMatteo, M. Robin. "Social support and patient adherence to medical treatment: a meta-analysis." (2004): 207.

[28] Broadbent, Elizabeth, et al. "The brief illness perception questionnaire." Journal of psychosomatic research 60.6 (2006): 631-637.

[29] Łuszczyńska, A., et al. "Berlińskie Skale Wsparcia Społecznego (BSSS). Wyniki wstępnych badań nad adaptacją skal i ich własnościami psychometrycznymi." Studia Psychologiczne 44.3 (2006): 17-27.

[30] Brzozowski P., Skala uczuć pozytywnych i negatywnych SUPIN. Polska adaptacja skali PANAS Davida Watsona i Lee Anny Clark. Podręcznik. Warszawa: Pracownia Testów Psychologicznych Polskiego Towarzystwa Psychologicznego, 2010.

[31] American Diabetes Association. "Diagnosis and classification of diabetes mellitus." Diabetes care 37.Supplement 1 (2014): S81-S90.

[32] Hood, Korey K., et al. "Depressive symptoms in children and adolescents with type 1 diabetes." Diabetes care 29.6 (2006): 1389-1389. 